JEL: C51, C55, F00, F02

\title{
ЭКОНОМЕТРИЧЕСКИЙ АНАЛИЗ ТОВАРООБОРОТА МЕЖДУ РОССИЕЙ И КИТАЕМ
}

\author{
(c) 2021 Трегуб Илона Владимировна \\ доктор экономических наук, профессор департамента математики \\ Финансовый университет при Правительстве Российской Федерации, Россия, Москва \\ E-mail: ilonavl_fa@mail.ru \\ (c) 2021 Байрамуков Локман Хусеинович \\ студент-магистр \\ Финансовый университет при Правительстве Российской Федерации, Россия, Москва \\ E-mail:lokman.bayramukov@gmail.com
}

Предмет/тема. Российская Федерация имеет хорошие партнерские отношения после установления стратегического сотрудничества с Китайской Народной Республикой уже на протяжении более чем 20 лет. Объектом моделирования в данной работе является товарооборот между Россией и Китаем.

Цель работы: Выявление особенности динамики товарооборота между Россией и Китаем за период 2016-2018 г.г. и выявление ключевых факторов, влияющих на эту динамику.

Методология. Для анализа данных используется методика регрессионного анализа и тестирования предпосылок теоремы Гаусса-Маркова, к числу которых относится тест Дарбина-Уотсона и тест Голдфелда-Квандта.

Результаты/Выводы. Исследование проводилось по нескольким направлениям: определение наличия гетероскедастичности; выявление положительных или отрицательных корреляций, а также определение значимости модели и взаимосвязи между статистическими данными. По результатам проведенных исследований был сделан ряд выводов.

Ключевые слова: анализ данных; регрессия, корреляционный анализ; регрессионный анализ; товарооборот; взаимоотношения; Россия; Китай; внешние инвестиции.

Российская Федерация имеет хорошие партнерские отношения после установления стратегического сотрудничества с Китайской Народной Республикой уже на протяжении более чем 20 лет. Стоит отметить, что КНР - это самый крупный покупатель российской нефти. Помимо этого, Китай является одной из тех стран, которые делают наибольший объем иностранных инвестиций в Российскую Федерацию. При этом последние несколько лет наблюдается стремительное укрепление экономики Китая, рынок которого включает в себя компании, которые вошли топ компаний мира. На данный момент китайская экономика сосредоточилась на внешних инвестициях. При этом растет уровень интереса китайских компаний к ведению бизнеса в России. Это связано и с такими долгосрочными проектами как Ямал СПГ, Свободный порт Владивосток и высокоскоростная железная дорога, соединяющая Москву и Пекин.

Российские компании, в свою очередь, заин- тересованы в китайском рынке ввиду того, что платежеспособность населения Китая стремительно растет ввиду укрепления данной страны на международной арене и улучшения ее экономики. То есть, можно сделать вывод о том, что Россия и Китай заинтересованы в инвестициях. Данный интерес неуклонно продолжает расти. Для поддержания роста инвестиций должны быть задействованы как местные партнеры, правительства, так и инвесторы.

Объектом моделирования в данной работе является товарооборот между Россией и Китаем.

Необходимо начать с построения спецификации эконометрической модели. Сюда будут входить определение объекта моделирования и выборка переменных модели.

Спецификация эконометрической модели:

$$
\begin{aligned}
Y_{t}= & b_{0}+X_{1 t} * b_{1}+X_{2 t} * b_{2}+X_{3 t} * b_{3}+X_{4 t} * b_{4} \\
& +X_{5 t} * b_{5}+X_{6 t} * b_{6}+X_{7 t} * b_{7}+\varepsilon_{t}
\end{aligned}
$$


Переменные:

$X_{1}$ - Курс юаня к рублю по статистике МосБиржи, рублей

Пара рубль-юань становится все более популярной. Курс юаня к рублю устанавливается напрямую (без участия доллара США) на базе заявок на покупку и продажу юаня в зависимости от спроса и предложения. Страны собираются переходить на национальные валюты в расчетах между ними.

$X_{2}$ - Цена на нефть Brent, \$ за баррель

Отношения между Россией и Китаем в первую очередь построены на экспорте нефти. Экспорт из России в Китай (около 80\%) составляет нефть.

$X_{3}$ - Объем добычи нефти, тысяч тонн

Как было сказано в пункте выше, основную часть экспорта из России в Китай составляет нефть.

$X_{4}$ - Курс доллара, рублей

Рубль слишком сильно привязан к доллару и зависит от его «настроения», основная часть торговых операций осуществляется в долларах. А в условиях геополитической напряженности и постоянно растущего санкционного бремени такая зависимость для нашей экономики смерти подобна.

$X_{5}$ - Объем торгов юанем на МосБирже, млрд. рублей

Объем торгов юанем показывает, насколько интересна эта валюта в России, а также ее необходимость в расчетах между двумя странами.

$X_{6}-$ Ключевая ставка ЦБ,\%

Ключевая ставка ЦБ является рычагом экономики России, от нее зависят многие экономические факторы.

$X_{7}-$ Торговый баланс, млрд. долл.

Так же нужно отметить общий фон внешнеэкономического состояния Российской Федерации, поэтому мы прибегаем к торговому балансу, который показывает разницу между экспортом и импортом.

Статистические данные, характеризующие объект моделирования. Описание исходных данных (значений переменных), которые будут использованы для настройки модели с обязательной ссылкой на источник данных (табл. 1).

Построена корреляционная матрица и проведен корреляционный анализ. Было выявлено, что связь между ключевой ставкой и ценой на нефть очень тесная, но так как корреляция между ключевой ставкой и товарооборотом меж- ду Россией и Китаем больше, то мы оставляем ключевую ставку и удаляем цену на нефть Brent (табл. 2).

Была получена матрица коэффициентов парной корреляция. Анализ матрицы коэффициентов парной корреляции показал, что факторы $\mathrm{X}_{6}$ и $\mathrm{X}_{2}(\mathrm{r}=-0,92), \mathrm{X}_{4}$ и $\mathrm{X}_{1}(\mathrm{r}=0,91), \mathrm{X}_{6}$ и $\mathrm{X}_{7}$ $(\mathrm{r}=-0,81)$ тесно связаны между собой, что свидетельствует о наличии мультиколлинеарности.

Для устранения мультиколлинеарности и выбора факторов для включения в модель подробнее рассмотрим матрицу коэффициентов парной корреляции. Анализ матрицы коэффициентов парной корреляции начинаем с анализа первого столбца матрицы, где расположены коэффициенты корреляции, отражающие тесноту связи, зависимой переменной объем продаж с включенными в анализ факторами. Анализ показывает, что зависимая переменная, т.е. товарооборот между Россией и Китаем, имеет тесную связь с ключевой ставкой ЦБ $(\mathrm{r}=-0,897)$, с ценой на нефть $(\mathrm{r}=0,88)$ и с торговым балансом $(\mathrm{r}=0,772)$. Факторы $\mathrm{X}_{3}, \mathrm{X}_{1}, \mathrm{X}_{4}, \mathrm{X}_{5}$ имеют слабую связь с зависимой переменной ( $\mathrm{r}=0,286$ и $r=-0,389)$.

Применяя регрессионный анализ методом наименьших квадратов, найдем оценки коэффициентов модели 1. Расчеты проведены в эконометрическом пакете “Gretl”. Результаты представлены на рисунке 1 .

Мы видим, что исправленное значение $\mathrm{R}^{2}=0,84$. Это означает, что $84 \%$ изменений в объеме товарооборота между Россией и Китаем объясняются курсом юаня к рублю, ценой на нефть марки Brent, объемом добычи нефти, курсом доллара, объемом торгов юанем на МосБирже, ключевой ставкой ЦБ, торговым балансом в рамках линейной модели регрессии.

Проверим значимость коэффициентов линейной регрессии с использованием Р-значения и сопоставим их с коэффициентами корреляции (табл. 3).

Сравнивая числовые значения $\mathrm{P}$ с уровнем значимости alpha равным 0,05 мы видим, что переменные объем добычи нефти, объем торгов юаня и торговый баланс являются незначимыми. Проверка предпосылок теоремы Гауса-Маркова показала автокорреляция отсутствует, но остатки гетероскедастичны. Гетероскедастичность остатков возникает из-за сильной корреляции остатков с переменной R и переменной T_B

Методом пошагового исключения незна- 
Таблица 1. Данные для построения модели.

\begin{tabular}{|c|c|c|c|c|c|c|c|c|}
\hline Дата & $\begin{array}{c}\text { Товаро- } \\
\text { оборот } \\
\text { между } \\
\text { Россией } \\
\text { и Китаем, } \\
\text { млрд. \$ }\end{array}$ & $\begin{array}{c}\text { Курс юаня } \\
\text { к рублю } \\
\text { по стат } \\
\text { МосБир- } \\
\text { жи, руб }\end{array}$ & $\begin{array}{c}\text { Цена на } \\
\text { нефть } \\
\text { Brent, \$ за } \\
\text { баррель }\end{array}$ & $\begin{array}{c}\text { Объем } \\
\text { добычи } \\
\text { нефти, } \\
\text { тыс тонн }\end{array}$ & $\begin{array}{l}\text { Курс дол- } \\
\text { лара, руб }\end{array}$ & $\begin{array}{c}\text { Объем } \\
\text { торгов } \\
\text { юанем на } \\
\text { МосБир- } \\
\text { же, млрд. } \\
\text { руб }\end{array}$ & $\begin{array}{c}\text { Ключевая } \\
\text { ставка } \\
\text { ЦБ,\% }\end{array}$ & $\begin{array}{c}\text { Торговый } \\
\text { баланс, } \\
\text { млрд. } \\
\text { долл. }\end{array}$ \\
\hline 01.01 .2016 & 3.81 & 11.44 & 31.88 & 46141.20 & 76.31 & 46.42 & 11.00 & 7.30 \\
\hline 01.02 .2016 & 4.45 & 11.50 & 33.73 & 43133.80 & 77.23 & 39.07 & 11.00 & 7.40 \\
\hline 01.03 .2016 & 5.20 & 10.39 & 40.30 & 46084.10 & 70.51 & 32.50 & 11.00 & 7.70 \\
\hline 01.04 .2016 & 4.37 & 9.98 & 43.55 & 44291.90 & 66.69 & 38.35 & 11.00 & 6.80 \\
\hline 01.05 .2016 & 4.79 & 10.15 & 48.05 & 45825.90 & 65.67 & 40.06 & 11.00 & 7.50 \\
\hline 01.06 .2016 & 5.61 & 9.63 & 49.96 & 44377.95 & 65.31 & 6.95 & 11.00 & 8.10 \\
\hline 01.07 .2016 & 5.26 & 9.95 & 46.86 & 45893.60 & 64.34 & 4.23 & 10.50 & 6.50 \\
\hline 01.08 .2016 & 6.58 & 9.78 & 47.77 & 45309.20 & 64.93 & 5.31 & 10.50 & 4.90 \\
\hline 01.09 .2016 & 6.38 & 9.42 & 47.09 & 45483.40 & 64.60 & 6.15 & 10.50 & 7.40 \\
\hline 01.10 .2016 & 6.08 & 9.35 & 51.65 & 47493.60 & 62.68 & 9.09 & 10.00 & 6.60 \\
\hline 01.11 .2016 & 5.36 & 9.28 & 46.85 & 45872.59 & 64.37 & 11.56 & 10.00 & 9.10 \\
\hline 01.12 .2016 & 7.35 & 8.65 & 54.71 & 47398.90 & 62.20 & 14.86 & 10.00 & 11.80 \\
\hline 01.01 .2017 & 6.00 & 8.81 & 55.70 & 46991.70 & 59.96 & 6.07 & 10.00 & 11.40 \\
\hline 01.02 .2017 & 5.66 & 8.53 & 56.17 & 42430.50 & 58.40 & 6.84 & 10.00 & 10.20 \\
\hline 01.03 .2017 & 6.75 & 8.18 & 51.86 & 46732.50 & 58.11 & 11.33 & 10.00 & 12.60 \\
\hline 01.04 .2017 & 6.04 & 8.24 & 53.72 & 45002.60 & 56.43 & 6.22 & 10.00 & 8.00 \\
\hline 01.05 .2017 & 6.58 & 8.40 & 51.69 & 46315.90 & 57.17 & 6.96 & 10.00 & 8.50 \\
\hline 01.06 .2017 & 7.29 & 8.69 & 47.76 & 44786.70 & 57.83 & 10.75 & 9.25 & 8.70 \\
\hline 01.07 .2017 & 5.43 & 8.89 & 48.81 & 46309.60 & 59.67 & 5.54 & 9.25 & 4.00 \\
\hline 01.08 .2017 & 8.54 & 8.80 & 51.95 & 46152.20 & 59.65 & 11.25 & 9.00 & 6.60 \\
\hline 01.09 .2017 & 7.19 & 8.67 & 55.39 & 44640.00 & 57.70 & 8.13 & 9.00 & 10.20 \\
\hline 01.10 .2017 & 7.32 & 8.82 & 57.22 & 46241.60 & 57.73 & 6.66 & 8.50 & 9.80 \\
\hline 01.11 .2017 & 8.67 & 8.84 & 62.89 & 44801.10 & 58.92 & 7.48 & 8.25 & 11.50 \\
\hline 01.12 .2017 & 9.37 & 8.89 & 63.46 & 46337.80 & 58.59 & 7.10 & 8.25 & 13.70 \\
\hline 01.01 .2018 & 8.44 & 8.94 & 69.07 & 46323.80 & 56.79 & 4.26 & 7.75 & 17.00 \\
\hline 01.02 .2018 & 7.54 & 8.89 & 65.52 & 41849.70 & 56.81 & 5.86 & 7.75 & 12.20 \\
\hline 01.03 .2018 & 8.11 & 9.15 & 65.65 & 46392.30 & 57.03 & 7.81 & 7.50 & 15.00 \\
\hline 01.04 .2018 & 8.06 & 9.95 & 72.03 & 44880.50 & 60.46 & 10.11 & 7.25 & 15.30 \\
\hline 01.05 .2018 & 8.64 & 9.74 & 77.26 & 46407.20 & 62.21 & 17.03 & 7.25 & 15.20 \\
\hline 01.06 .2018 & 9.12 & 9.46 & 76.07 & 45292.30 & 62.71 & 9.37 & 7.25 & 15.60 \\
\hline 01.07 .2018 & 9.33 & 9.19 & 74.87 & 47442.90 & 62.88 & 28.09 & 7.25 & 13.40 \\
\hline 01.08 .2018 & 9.63 & 9.86 & 73.13 & 47429.00 & 66.12 & 15.91 & 7.25 & 15.80 \\
\hline 01.09 .2018 & 9.75 & 9.53 & 78.69 & 46527.30 & 67.66 & 13.16 & 7.25 & 18.50 \\
\hline
\end{tabular}

Таблица 2. Корреляционная матрица.

\begin{tabular}{|l|l|l|l|l|l|l|l|l|}
\hline & \multicolumn{1}{|c|}{$Y$} & $X_{1}$ & $X_{2}$ & $X_{3}$ & $X_{4}$ & $X_{5}$ & $X_{6}$ & $X_{7}$ \\
\hline Ү, Товарооборот между Россией и Китаем, млрд. \$ & 1 & & & & & & & \\
\hline Курс юаня к рублю по стат МосБиржи, руб & -0.39 & 1 & & & & & & \\
\hline Цена на нефть Вrent, \$ за баррель & 0.88 & -0.34 & 1 & & & & & \\
\hline Объем добычи нефти, тыс тонн & 0.29 & -0.09 & 0.20 & 1 & & & & \\
\hline Курс доллара, руб & -0.44 & 0.91 & -0.44 & 0.00 & 1 & & & \\
\hline Объем торгов юанем на МосБирже, млрд. руб & -0.42 & 0.73 & -0.39 & 0.00 & 0.76 & 1 & & \\
\hline Ключевая ставка ЦБ,\% & -0.90 & 0.27 & -0.92 & -0.17 & 0.43 & 0.35 & 1 & \\
\hline Торговый баланс, млрд. долл. & 0.77 & -0.17 & 0.86 & 0.19 & -0.24 & -0.18 & -0.81 & 1 \\
\hline
\end{tabular}




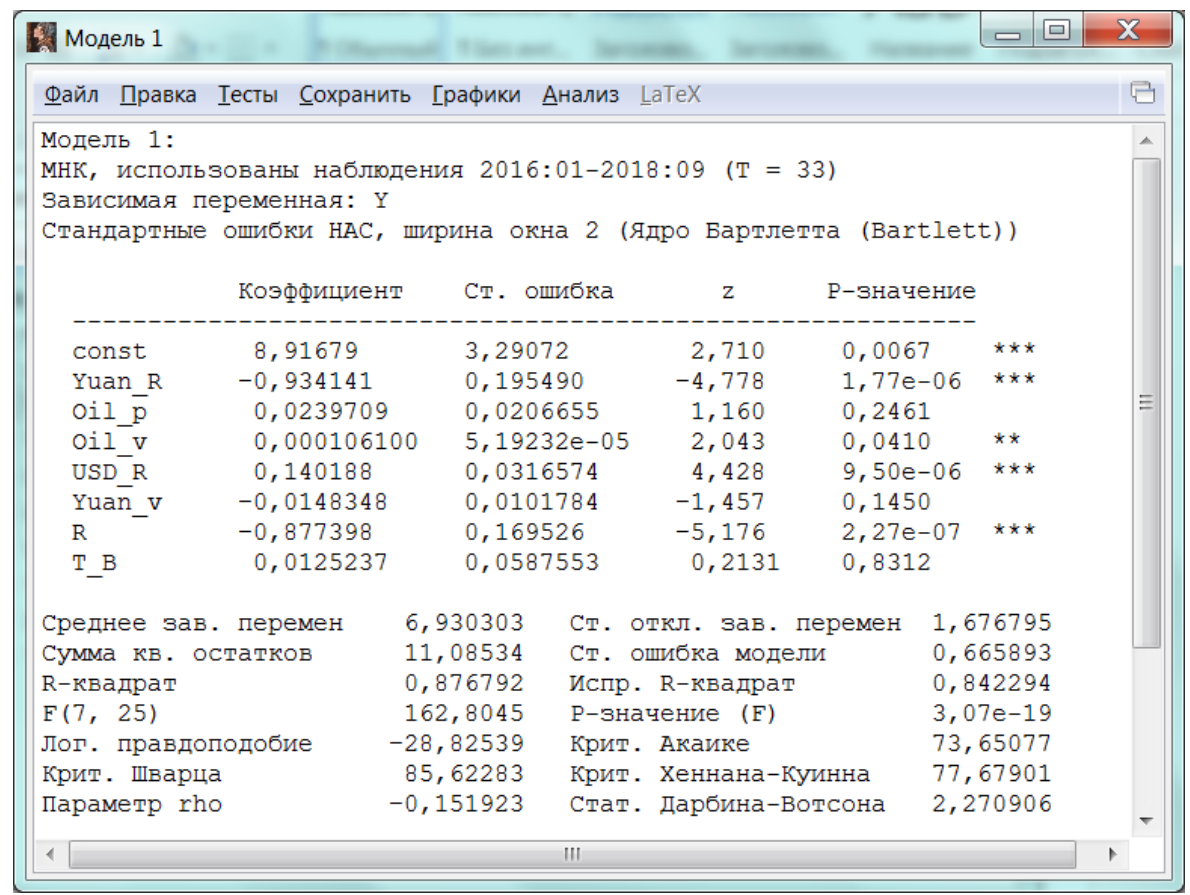

Рисунок 1. Выходные статистики модели 1.

На рисунке приведены следующие обозначения:

Y - Товарооборот между Россией и Китаем, млрд. \$;

Yuan_R - курс юаня к рублю по стат МосБиржи, руб;

Oil_p - цена на нефть Brent, \$ за баррель;

Oil-v - объем добычи нефти, тыс тонн;

USD_R - курс доллара, руб;

Yuan_v - объем торгов юанем на МосБирже, млрд. руб;

$\mathrm{R}$ - ключевая ставка ЦБ,\%;

T_B - торговый баланс, млрд. долл.

Таблица 3. Матрица коэффициентов парной регрессии.

\begin{tabular}{|l|c|c|}
\hline \multicolumn{1}{|c|}{ Факторы } & $\begin{array}{c}\text { Коэффициенты корреляции } \\
\text { Ү с факторами X }\end{array}$ & Р-значение \\
\hline Курс юаня к рублю по стат МосБиржи, руб & -0.39 & $1,77 \mathrm{e}-06$ \\
\hline Цена на нефть Brent, \$ за баррель & 0.88 & 0,25 \\
\hline Объем добычи нефти, тыс тонн & 0.29 & 0,04 \\
\hline Курс доллара, руб & -0.44 & $9,50 \mathrm{e}-06$ \\
\hline Объем торгов юанем на МосБирже, млрд. руб & -0.42 & 0,15 \\
\hline Ключевая ставка ЦБ,\% & -0.90 & $2,27 \mathrm{e}-07$ \\
\hline Торговый баланс, млрд. долл. & 0.77 & 0,83 \\
\hline
\end{tabular}

чимых переменных из модели с одновременной проверкой предпосылок теоремы ГауссаМаркова получили итоговую модель.

Оценки коэффициентов и выходные статистики представлены на рисунке 2.

Коэффициент детерминации показывает долю дисперсии товарооборота между Россией и Китаем, объясняемую включенными в модель факторами. Здесь он принимается значение
$\mathrm{R}^{\wedge} 2=0,85$, что показывает очень хорошую объясняющую способность модели.

Значимость модели регрессии в целом проверяется критерием Фишера. С помощью критерия Фишера мы проверяем гипотезу о равенстве нулю коэффициента детерминации. если $\mathrm{F}_{\text {набл }}>$

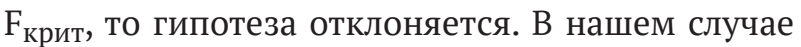
$\mathrm{F}_{\text {набл }}=100,33$, что больше $\mathrm{F}_{\text {крит }}=4,16$ (найдено с помощью функции FРАСПОБР). Значит гипотеза 


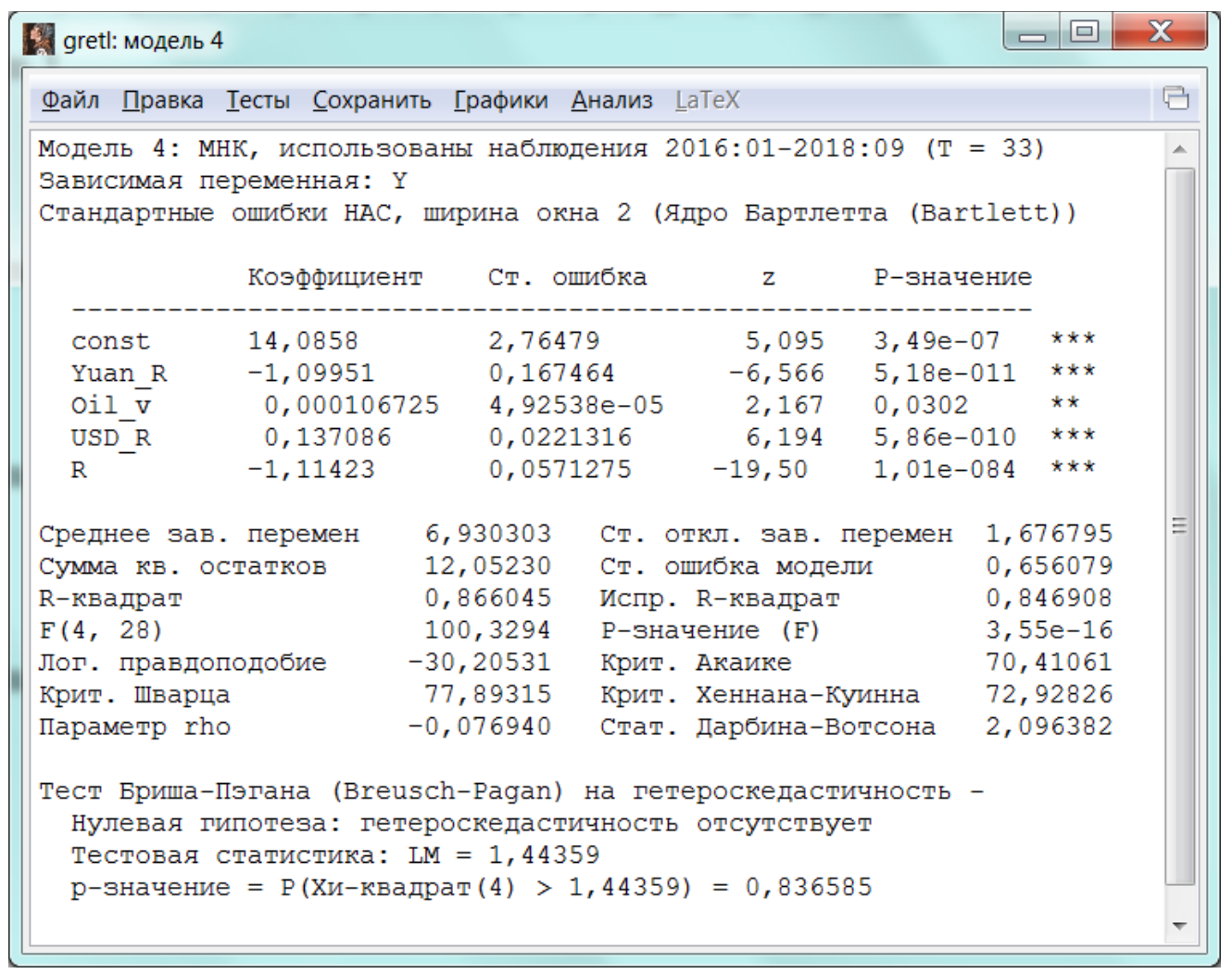

Рисунок 2. Выходные статистики итоговой модели.

о равенстве коэффициента детерминации нулю отклоняется. Модель обладает высоким качеством спецификации и прогностической способностью.

Все предпосылки теоремы Гауса-Маркова выполняются. Оценки коэффициентов модели обладают свойством состоятельности, несмещенности, эффективности и точности.

Средняя ошибка апроксимации получилась меньше 10\%, значит модель можно признать точной и пригодной для прогнозирования.

Предсказанные по модели значения 95\% доверительных интервалов, $\mathrm{t}(28,0,025)=2,048$ представлены в таблице 4 .

На основе представленной таблицы можно построить график, демонстрирующий эмпирические и модельные данные (рис. 3).

При построении 90\%-ные доверительные интервалы у нас получилось, что в июле 2017 года товарооборот между Россией и Китаем был завышен по сравнению с полученным интервалом. А также в августе и декабре 2017 года товарооборот между Россией и Китаем был занижен по сравнению с полученным интервалом.

Таким образом, исходя из результатов моделирования можно сделать следующие выво- ды. При увеличении ключевой ставки ЦБ на 1 процентный пункт объем товарооборота между Россией и Китаем уменьшается на 1,1 млрд. дол. Это в первую очередь связано с тем, что при увеличении ключевой ставки ЦБ происходит увеличение стоимости привлечения кредитов компаниями от коммерческих банков. Новым компаниям, которые не имеют достаточный объем ресурсов становится тяжелее выйти на такой конкурентный рынок. Плюс при увеличении затрат на выплату задолженности по кредитам уменьшается рентабельность деятельности и бизнес предпочитает переключить внимание на другие более прибыльные сферы.

Увеличение курса доллара к рублю на 1 пункт ведет к увеличению товарооборота между Россией и Китаем на 1,14 млрд. Это объясняется тем, что большинство транзакций между компаниями России и Китая происходят в международной валюте, в долларах. И если позиция доллара укрепляется российские компании, которые получают доходы в данной валюте, могут получить дополнительно и доходы, связанные с изменением валютных курсов при их конвертации в рубли.

Увеличение объема добычи нефти на 1 тыс.т. 
Таблица 4. Итоговые данные с предсказаниями для построения графика.

\begin{tabular}{|c|c|c|c|c|}
\hline Набл. & $\mathrm{Y}$ & Предсказание & Ст. ошибка & $\begin{array}{c}\text { 95\% доверительный } \\
\text { интервал }\end{array}$ \\
\hline $2016-1$ & 3,81 & 4,64 & 0,71 & $(3,18,6,10)$ \\
\hline $2016-2$ & 4,45 & 4,38 & 0,71 & $(2,92,5,83)$ \\
\hline $2016-3$ & 5,2 & 4,99 & 0,69 & $(3,58,6,39)$ \\
\hline $2016-4$ & 4,37 & 4,73 & 0,68 & $(3,33,6,12)$ \\
\hline $2016-5$ & 4,79 & 4,57 & 0,69 & $(3,15,5,97)$ \\
\hline $2016-6$ & 5,61 & 4,94 & 0,68 & $(3,54,6,32)$ \\
\hline $2016-7$ & 5,26 & 5,16 & 0,68 & $(3,76,6,55)$ \\
\hline $2016-8$ & 6,58 & 5,37 & 0,67 & $(3,99,6,75)$ \\
\hline $2016-9$ & 6,38 & 5,74 & 0,67 & $(4,36,7,11)$ \\
\hline $2016-10$ & 6,08 & 6,33 & 0,67 & $(4,95,7,71)$ \\
\hline $2016-11$ & 5,36 & 6,46 & 0,67 & $(5,09,7,82)$ \\
\hline $2016-12$ & 7,35 & 7,01 & 0,67 & $(5,64,8,39)$ \\
\hline $2017-1$ & 6 & 6,49 & 0,67 & $(5,11,7,86)$ \\
\hline $2017-2$ & 5,66 & 6,1 & 0,7 & $(4,68,7,53)$ \\
\hline $2017-3$ & 6,75 & 6,9 & 0,68 & $(5,52,8,28)$ \\
\hline $2017-4$ & 6,04 & 6,42 & 0,68 & $(5,03,7,81)$ \\
\hline $2017-5$ & 6,58 & 6,49 & 0,67 & $(5,12,7,87)$ \\
\hline $2017-6$ & 7,29 & 6,93 & 0,67 & $(5,56,8,30)$ \\
\hline 2017-7 & 5,43 & 7,13 & 0,67 & $(5,77,8,49)$ \\
\hline $2017-8$ & 8,54 & 7,49 & 0,66 & $(6,13,8,85)$ \\
\hline $2017-9$ & 7,19 & 7,2 & 0,67 & $(5,83,8,58)$ \\
\hline $2017-10$ & 7,32 & 7,78 & 0,67 & $(6,41,9,13)$ \\
\hline 2017-11 & 8,67 & 8,04 & 0,67 & $(6,67,9,40)$ \\
\hline 2017-12 & 9,37 & 8,1 & 0,67 & $(6,73,9,46)$ \\
\hline $2018-1$ & 8,44 & 8,35 & 0,67 & $(6,98,9,72)$ \\
\hline 2018-2 & 7,54 & 7,94 & 0,7 & $(6,51,9,36)$ \\
\hline $2018-3$ & 8,11 & 8,44 & 0,67 & $(7,06,9,82)$ \\
\hline 2018-4 & 8,06 & 8,14 & 0,68 & $(6,75,9,53)$ \\
\hline $2018-5$ & 8,64 & 8,77 & 0,67 & $(7,41,10,15)$ \\
\hline $2018-6$ & 9,12 & 9,04 & 0,67 & $(7,67,10,40)$ \\
\hline 2018-7 & 9,33 & 9,59 & 0,67 & $(8,22,10,97)$ \\
\hline 2018-8 & 9,63 & 9,3 & 0,67 & $(7,92,10,68)$ \\
\hline $2018-9$ & 9,75 & 9,77 & 0,67 & $(8,39,11,14)$ \\
\hline
\end{tabular}




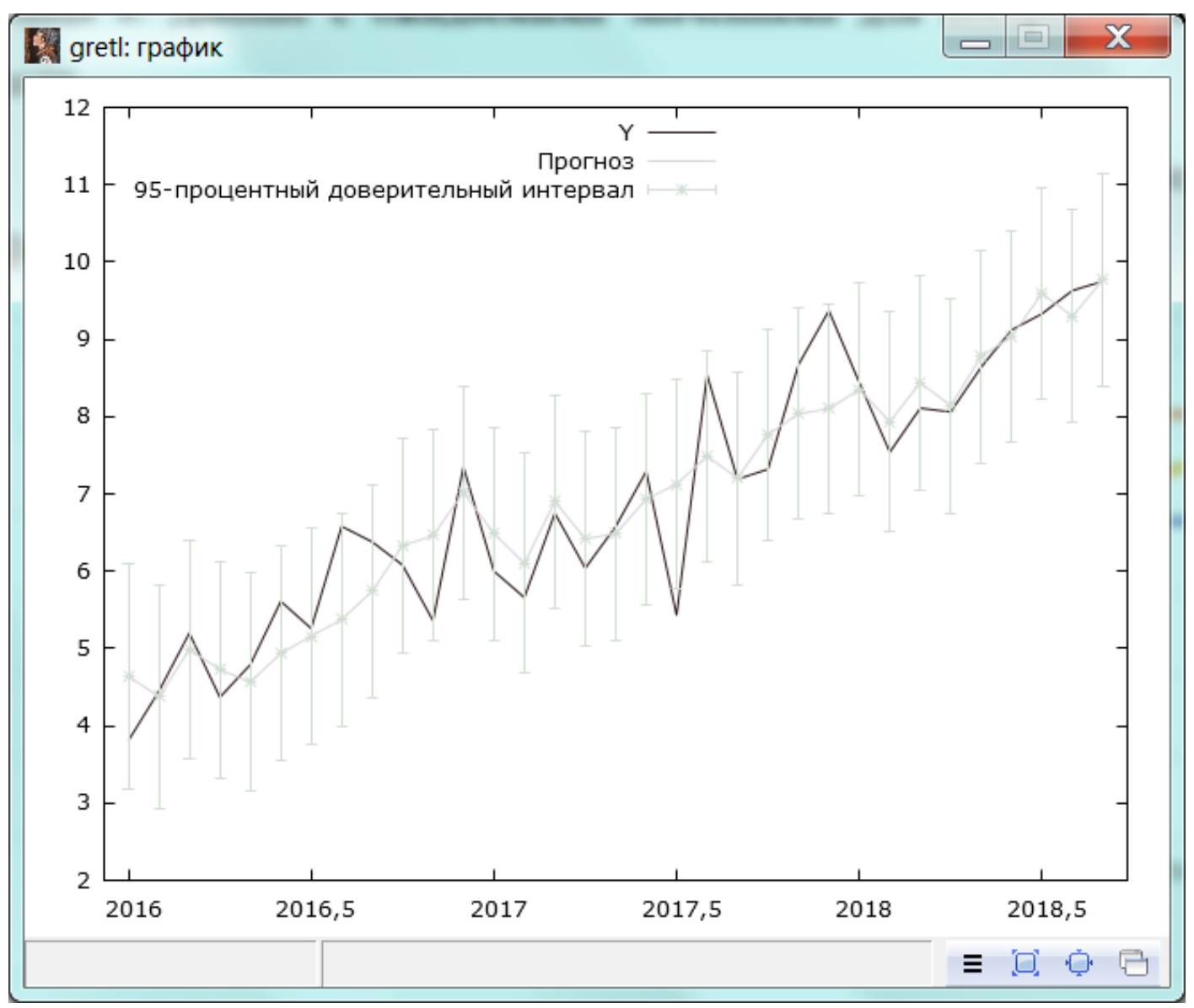

Рисунок 3. Графическая иллюстрация модели товарооборота между Россией и Китаем.

ведет к увеличению товарооборота на 0,1 млн. дол. Тут наблюдается прямая связь и объясняется это тем, что Россия является главным поставщиком сырьевых ресурсов в Китайскую Народную Республику. Таким образом, мы видим прямое влияние увеличение объема добычи нефти в России и ее продажа, в том числе и Китаю, прямо влияет на увеличение товарооборота между данными странами.

Усиление национальной валюты Китая по отношению к национальной валюте России ведет к усилению товарооборота между этими странами. Как и говорилось в начале данной статьи китайский бизнес благодаря укреплению своих позиций и увеличению свободных ресурсов начал искать им наиболее эффективное применение. И Россия как страна с огромным сырьевыми запасами, квалифицированными кадрами и огромной незаселенной территорией, заинтересовала китайские компании, которые начали открывать в РФ свои представительства. Данные представительства реализуют продук- цию, произведенную в Китае, и укрепление валюты Китая напрямую влияет на устойчивость данных компаний. Такие устойчивые компании, в свою очередь, продолжают наращивать объем товарооборота.

Исходя из вышесказанного следует сделать вывод о том, что изменения в товарообороте частично положительны. Однако, стоит отметить, что для российской стороны данное изменение на данный момент происходит в основном за счет укрепления позиции доллара к рублю, а также изменений цен на нефть. Для Китайской стороны наоборот увеличение товарооборота происходит за счет укрепления позиции их национальной валюты, а также укрепления позиции китайских компаний.

Россия извлекает из этого выгоды. Однако в долгосрочной перспективе, при сохранении данных условий: дальнейшего ослаблении конкурентных преимуществ российских компаний ввиду неспособности развиваться в таких жестких условиях и снижения ценности для Китая 
как сырьевого экспортера, торговый баланс нашей страны с КНР может сильно исказиться в негативную сторону.

Это все указывает на то, что государству необходимо немного ограничить полномочия представительств китайских компаний, чтобы сохранить жизнеспособность российского бизнеса. А также необходимо диверсифицировать продукцию, которая поставляется с нашей стороны Китаю. То есть государству необходимо стремиться к тому, чтобы изменение объема добычи полезных ископаемых и изменение цены на нефть марки Brent не сказывались так сильно на изменении товарооборота между Россией и Китаем, так как на данный момент данная зависимость весьма значительна.

\section{Библиографический список}

1. Трегуб И. В. Эконометрика. Модель реальной системы. М .: 2016.164 с.

2. Трегуб И. В. Математические модели динамики экономических систем: монография - М .: РУСАЙНС, 2018.$164 \mathrm{c}$.

3. Трегуб И.В.Эконометрические исследования. Практические примеры. Эконометрические исследования. Практические примеры.-М .: Лань, 2017. 164 с.

4. Трегуб И. В. Эконометрика на английском языке. Руководство. Москва: 2017

5. Экспорт и импорт России по товарам и странам. URL: http://ru-stat.com/date-M201701-201809/RU/trade/CN

6. Валютный рынок. Курс юаня к рублю. URL: https://www.moex.com/ru/issue/CNYRUB_TOM/CETS

7. Свежие данные с Биржи Intercontinental Exchange. URL: http://bhom.ru/commodities/neft-brent/?sb=yes\&sta rtdate $=01.01 .2017$ \&enddate $=01.09 .2018$

8. Министерство энергетики. Статистика. URL: https://minenergo.gov.ru/activity/statistic

9. Валютный рынок. Курс доллара к рублю. URL: https://mainfin.ru/currency/cb-rf/date/2018

10. Валютный рынок. Объем торгов юанем на МосБирже. URL: https://www.moex.com/ru/issue/CNYRUB_TOM/ CETS

11. КонсультантПлюс. Ключевая ставка, установленная Банком России. URL: http://www.consultant.ru/ document/cons_doc_LAW_12453/886577905315979b26c9032d79cb911cc8fa7e69/

12. Вся статистика: Страны мира (по месяцам), Россия. URL: http://www.ereport.ru/stat.php?razdel=monthly\&co unt $=$ ru\&table $=$ rutrbal\&time $=1$ 